\title{
ESPAÇOS ALTERNATIVOS DE APRENDIZAGEM: PESQUISA EXPLORATÓRIA SOBRE PRÊMIOS E CONCURSOS UNIVERSITÁRIOS NO BRASIL
}

\author{
ALTERNATIVE LEARNING SPACES: EXPLORATORY RESEARCH ABOUT COLLEGE
}

AWARDS AND CONTESTS IN BRAZIL

\author{
Recebido em: 16/09/2016 • Aprovado em: 29/11/2016 \\ Avaliado pelo sistema double blind review \\ Editora Científica: Claudia Stadtlober \\ DOI 10.13058/raep.2017.v18n1.493
}

\section{EDSONSADAO IIZUKA esadao@fei.edu.br}

\author{
CENTRO UNIVERSITÁRIO FEI
}

\begin{abstract}
RESUMO
As metodologias ativas de aprendizado têm sido objeto de atenção dos pesquisadores da área de Administração no Brasil. E, com base em conversas não estruturadas com docentes de uma determinada Instituição de Ensino Superior (IES), percebeu-se que um professor se utilizava dos prêmios e concursos universitários como uma alternativa inovadora de aprendizagem aos seus alunos. Essa experiência exitosa, porém isolada, deste docente inspirou esta pesquisa exploratória. Seriam, portanto, os prêmios e os concursos universitários espaços alternativos para aprendizado dos estudantes de Administração? Qual é a literatura acadêmica nesta temática e quais são os exemplos empíricos no país? E, finalmente, será que a experiência desse docente pode ser disseminada entre seus colegas na IES? A pesquisa adota uma abordagem qualitativa, de caráter exploratório, e caracteriza-se por ser uma investigação aplicada. Além do levantamento e da sistematização das referências, utilizaram-se a observação participante e as entrevistas não estruturadas com docentes e discentes e entrevistas semiestruturadas com dirigentes da IES. Os resultados apontaram o seguinte: i) os prêmios e concursos universitários podem ser considerados atividades de aprendizagem; ii) apresentaram-se a literatura sobre prêmios, metodologias ativas, especialmente PBL e também casos concretos no país e, finalmente, iii) a pesquisa indicou que a experiência exitosa e isolada do docente pode ser disseminada, em parte, entre os docentes da IES pesquisada. Palavras-chave: Metodologias ativas; Aprendizagem; Prêmios e concursos universitários.
\end{abstract}

\begin{abstract}
Active learning methodologies have been privileged as a research object by scholars of the Business Administration area in Brazil. Based on unstructured conversations with professors in a specific HEI (Higher Education Institution), we realized that one of them was using college awards and contests as an innovative learning alternative for his students. This successful but unique experience of this professor inspired this exploratory research. Could college awards and contests be an alternative learning space for Business Administration students? Is there academic literature about this debate? Are there empirical examples in Brazil? And, finally, could the experience of this professor be disseminated among his colleagues at the institution? The research presents a qualitative and exploratory approach and is characterized as an applied research. In addition to the bibliographic survey and systematization of the references, the research methodology also involved participant observation, unstructured interviews with professors and students and semi-structured interviews with the HEI administrators. The results indicate that i) college awards and contests can be considered as learning activities; ii) there are academic literature about college awards, active methodologies - especially PBL (problem based learning) - and there are empirical cases in Brazil; and finally iii) the investigation shows that the successful and unique experience of the professor who inspired our inquiries can be disseminated, in part, among his colleagues at the HEI where the research was carried out.
\end{abstract}

Keywords: Active methodologies; Learning; College awards and contests. 


\section{INTRODUÇÃO}

Num contexto de expansão acelerada do ensino superior em Administração no Brasil, desde meados da década de 1990, os desafios para o ensino e a aprendizagem, com qualidade e profundidade, parecem ser intransponíveis. Os professores, em geral, são mal remunerados e nem sempre são preparados e até mesmo motivados para o exercício da docência; as Instituições de Ensino Superior (IES) necessitam, muitas vezes, de bons laboratórios, bibliotecas atualizadas e com volume adequado de livros e outras referências, salas de aula abarrotadas e com infraestrutura deficiente em termos de iluminação, materiais e equipamentos, cadeiras e até mesmo limpeza; os alunos, principalmente do período noturno, encontram-se cansados e estressados após uma longa jornada de trabalho, assim, nem sempre veem sentido nos cursos e nas disciplinas, reduzindo ainda mais o (pouco) estímulo e a motivação para estudar e aprender.

Parece haver consenso entre os pesquisadores sobre as limitações dos métodos tradicionais de ensino e aprendizagem. A simples memorização de conteúdos não aparenta ser uma alternativa adequada para um mundo que exige, cada vez mais, conhecimentos dinâmicos, iniciativas e comportamento na compreensão e resolução de problemas. Entretanto, por que diversos professores insistem em aulas expositivas, avaliações que medem o quanto se memoriza determinado conteúdo, num caminho de mão única na qual o docente é o "dono" do saber e o aluno mero "receptor" de informações? A resposta para esse tipo de indagação não parece ser simples, mas a comodidade para ambos os lados (alunos e professores) indica a permanência desse tipo de estratégia de ensino.

Além dessa possível comodidade, torna-se necessária a consideração sobre o processo produtivista presente em diversas instituições de ensino do país, tal como afirmou Alcadipani (2011b, p. 347): "na lógica da academia produtivista, o tempo para reflexão é deixado de lado, a formação de alunos é escamoteada e o desenvolvimento intelectual significa apenas números em uma tabela". Nesse sentido, parece ser importante resgatar o debate sobre a "linha de montagem" na "fábrica de administradores", na 
qual os alunos e professores ausentam-se de um processo de evolução crítico-reflexiva (NICOLINI, 2003).

Nesse contexto, considerações de que as instituições de ensino superior se assemelham às redes de fast-food, nas quais os alunos são submetidos a instrumentos e processos de ensino cada vez mais padronizados, reforçam a ideia de que os espaços para reflexões e autonomia são escassos (ALCADIPANI; BRESLER, 1999; NICOLINI, 2003; ALCADIPANI, 2011a; ALMEIDA et al, 2011).

Esse tipo de educação cujos alunos são seres vazios e funcionam como receptáculos de informação, sem senso crítico, participação e reflexão, denomina-se educação bancária. O estudante nada mais é do que um "produto" alienado que se adapta ao meio e não se vê como protagonista no mundo em que vive, ou seja, anulando ou reduzindo seu poder de criação e transformação (FREIRE, 1983).

Nesse mesmo sentido, ao analisar o papel coadjuvante dos estudantes, argumenta Nicolini (2003, p. 51): "quanto mais memorizam, menos críticos se tornam e com isso distanciam-se, assim, de seu papel como sujeito do processo de aprendizagem". Em contraposição, uma educação problematizante possibilita que os alunos se transformem em protagonistas da sua história, que sejam capazes de refletir e agir com autonomia em diversos contextos da vida pessoal e profissional (NICOLINI, 2003).

Entretanto a busca por opções atinentes a um processo de ensino ativo e problematizador não é uma tarefa trivial, e as respostas, provavelmente, são diversas e perpassam por inúmeros fatores. Por sua vez, é preciso reconhecer que em determinadas IES, docentes e alunos dos cursos de Administração estão em busca de opções para a melhoria no processo de ensino e aprendizagem. Com base em conversas informais em uma dessas IES da área de Administração, foi possível perceber que os docentes, cada qual à sua maneira, procuram alternativas para a melhoria das aulas e, por conseguinte, ao aprendizado dos alunos.

Parte desses docentes tem utilizado casos de ensino ou mesmo recortes de jornais de negócio para promover a análise e o debate de situações concretas nas empresas; outra parte dos professores tem estimulado que 
seus alunos façam pesquisas sobre as empresas em que trabalham, dessa maneira, buscando a compreensão de problemas e as soluções; há, ainda, aqueles que estão utilizando serious game e jogos de empresas em sala de aula ou nos laboratórios. Cabe mencionar que parte dos professores simplesmente não tem feito nada além das aulas tradicionais e quase todos têm reclamado do desinteresse e despreparo dos alunos em suas disciplinas, ou seja, atribuído aos alunos a responsabilidade e, principalmente, a culpa pelo não aprendizado.

Um dos docentes dessa IES mencionou o uso dos prêmios e concursos universitários como um meio complementar de aprendizado entre seus alunos. Este docente trabalha com as disciplinas de empreendedorismo e relatou duas experiências recentes com prêmios e concursos universitários: a primeira experiência ocorreu numa prêmio para as melhores propostas de negócios sociais (empresas que geram benefícios socioambientais) ao qual todos os alunos e professores da IES foram convidados - entre os três vencedores, o primeiro e o terceiro lugares ficaram com equipes da turma, mas todos os alunos reconheceram essa atividade como uma das melhores que fizeram durante o seu período universitário; a segunda experiência foi com um prêmio promovido por um banco, no qual um dos alunos inscreveu-se com uma proposta inovadora e ficou entre os melhores no Brasil. O discente, a convite do professor, relatou a sua vivência aos colegas de Administração e, com isso, inspirou outros a participarem de prêmios e concursos universitários. Em função do prêmio, logo após a sua formatura, o discente foi convidado a trabalhar em projetos inovadores.

Essa prática chamou atenção dos colegas e impulsionou a presente pesquisa. E, sob tal perspectiva, formularam-se as seguintes questões de pesquisa: em que medida os prêmios e concursos universitários podem se constituir como espaços alternativos de aprendizagem? Quais são as referências teóricas e empíricas sobre o assunto? E, finalmente, a experiência isolada do docente pode ser relevante à IES e aos demais docentes dessa IES?

Pretende-se, dessa maneira, contribuir com os debates acerca de alternativas inovadoras de ensino e aprendizagem. Os objetivos deste estudo exploratório incluem: i) reunir a literatura acadêmica e científica sobre prê- 
mios e concursos; ii) analisar pesquisas anteriores sobre o tema; iii) verificar quais são os prêmios e concursos universitários existentes no Brasil e, finalmente, iv) compreender em que medida os prêmios e concursos universitários se constituem como alternativa para o ensino e aprendizagem na IES. A despeito de o foco inicial ser uma determinada IES, acredita-se que o resultado possa ser relevante às demais IES da área de Administração, seja para uma reflexão inicial sobre o assunto, seja para adotar uma prática alternativa de aprendizagem.

O artigo está estruturado em mais cinco partes além desta introdução. A revisão teórica aborda a produção científica sobre prêmios e concursos, o uso dos prêmios e concursos no contexto de ensino e aprendizagem e a comparação dos prêmios e concursos com as metodologias ativas e o problem based learning ( $\mathrm{PBL}$ ), que se constituem como lentes teóricas neste trabalho. Como próximo passo, apresenta-se o percurso metodológico da pesquisa e, em seguida, os resultados e as análises. Finalmente, são apresentadas as considerações finais e referências utilizadas nesta pesquisa. 


\section{REFERENCIAL TEÓRICO}

\section{OS PREAMIOS E CONCURSOS}

Os prêmios e concursos existem há muito anos e em diversos campos do conhecimento. Num levantamento histórico sobre prêmios e concursos, Ballantyne (2014) elencou algumas iniciativas, tais como Prêmio Espanhol de Longitude de 1567 (época das grandes navegações); Prêmio de Conservação de Alimentos de Napoleão (1795); Prêmio das Estradas de Ferro e Locomotivas de Liverpool e Manchester (1829); O Prêmio Orteig - para o primeiro aviador a voar sem escalas de Nova York a Paris - desafio vencido por Charles Lindberg (1919-1927); Prêmio Fundação Rockefeller para Rápido STD Teste de Diagnóstico (1994); Desafio Lunar Google (2007) - para soluções de baixo custo de exploração robótica; Concurso de Inovação Social para Nápoles-Itália (2011), entre outros (FREY, 2006; FREY; NECKERMANN, 2008; BALLANTYNE, 2014).

Apesar dessa presença ao longo da história e com resultados aparentemente relevantes, a produção acadêmica no Brasil sobre tal temática é incipiente. Em termos acadêmicos, economistas, psicólogos e sociólogos são os que têm se dedicado a conhecer os prêmios e concursos (FREY, 2006; FREY; NECKERMANN, 2008; BALLANTYNE, 2014). Por sua vez, vale observar que a quantidade de prêmios, bem como as organizações que têm oferecido esse tipo de distinção, tem aumentado ao longo dos últimos anos (BEST, 2008).

Para Harrison e Jepsen (2015, p. 1), os prêmios:

"podem se referir a uma medalha, uma condecoração, uma concessão, um certificado, um troféu, uma honraria, um recorde ou um campeonato. Eles incluem uma diversidade de organizações, tais como publicidade, artes, cinema, comida, literatura, música, ciência e televisão. Estes prêmios podem ser concedidos a uma organização, equipe ou indivíduo. Os prêmios reconhecem uma única atividade de longo prazo ou pode até mesmo ser concedido postumamente". 
Frey e Gallus (2014) comentam o seguinte:

"os prêmios na forma de medalhas, ordens e títulos são muitas vezes consideradas como 'ridículos' [...] eles parecem ser um desperdício de tempo e clara recursos. Isto é particularmente o caso como prêmios que são normalmente dadas aos gestores de topo cujos custos de oportunidade do tempo são os mais elevados".

De fato, com a diversidade de prêmios e concursos existentes, é preciso considerar caso a caso para saber se há relevância, transparência e seriedade (FREY; GALLUS, 2014).

Afinal, o que são os prêmios e concursos? Os autores Bastos, Kuuluvainen e Braga (2015, p. 5) definem os prêmios como: “[...] concursos que oferecem recompensas para indivíduos ou organizações que desenvolveram uma solução para um desafio definido”.

De acordo com Ballantyne (2014, p. 4):

"prêmios são uma ideia muito simples. Você identifica um problema, divulga-o e oferece uma recompensa para quem encontrar a melhor solução. Você atrai o interesse das pessoas com expertise e conhecimento [...] os prêmios são uma forma testada e comprovada para apoiar e acelerar a mudança no mundo".

Ademais, as pessoas utilizam-se de prêmios para chamar atenção para determinados problemas (em geral, negligenciados), encorajar pessoas para que invistam seu tempo e conhecimento para resolver problemas e promover avanços, propor e criar novos produtos e serviços, reunir informações e dados sobre um setor ou tema específico, identificar práticas exitosas e ideias inovadoras e, também, para localizar talentos emergentes e apoiar a entrada desses jovens no mercado (BALLANTYNE, 2014).

A literatura sobre prêmios e concursos parece indicar que se tratam de iniciativas que possibilitam espaços para atuação individual ou coletiva 
em torno de resolução de problemas e desafios. Em troca, os vencedores recebem distinções, simbólicas, e, em alguns casos, materiais.

\section{PREAMIOS E CONCURSOS COM MEIO DE APRENDIZAGEM}

De acordo com a literatura, os prêmios e concursos são iniciativas que tendem a ampliar as oportunidades para que estudantes do ensino médio, universitários, MBAs e até mesmo profissionais seniores coloquem em prática seus conhecimentos e suas habilidades na busca de melhorias e soluções de problemas e desafios presentes em organizações do mercado, da sociedade civil e do governo (FREY, 2006; FREY; NECKERMANN, 2008; BALLANTY$\mathrm{NE}, 2014)$. Isso parece ser um ponto pacífico entre os autores pesquisados. Entretanto em que medida isso se relaciona com um processo de aprendizado?

As pesquisas que relacionam os prêmios e concursos com um processo de aprendizado são incipientes no mundo, e, no Brasil, não se encontrou texto acadêmico que tratasse desse assunto. Entretanto as experiências empíricas e a troca de ideias entre os professores da IES pesquisada apontam para uma linha promissora de investigação. Ou seja, conquanto não exista uma literatura acadêmica desenvolvida no país, as experiências docentes e discentes na IES demonstraram ser plausível questionar a relação entre os prêmios e o processo de aprendizado na IES.

Os pesquisadores suecos Bastos, Kuuluvainen e Braga, do Instituto de Tecnologia de Karlskrona, elaboraram uma pesquisa sobre prêmios relacionados às questões socioambientais e apresentaram um questionamento semelhante ao proposto nesta pesquisa, ou seja, podem-se considerar os prêmios e concursos universitários como espaços alternativos para aprendizagem? Nesse sentido, Bastos, Kuuluvainen e Braga (2015, p. 6) afirmaram:

[...] um resultado muitas vezes esquecido como fruto dos Prêmios é que eles podem funcionar como ambientes de aprendizagem [...] (prêmio) tem potencial para criar um espaço para a experimentação, promovendo soluções mais eficazes, em um espaço colaborativo, no qual atuam diversos participantes, com uma variedade de ideias. 
Outros pesquisadores, tais como Biggs e Tang (2007), chegaram à conclusão de que os alunos são envolvidos numa escala que se inicia com a memorização, evolui para a anotação, descrição, explicação, relacionamento (teoria e prática), na aplicação e chegam até mesmo na teorização das atividades e de que isso estava diretamente relacionado aos métodos de ensino passivo (início da escala de envolvimento) até os métodos ativos, pelos quais os estudantes conseguem relacionar, aplicar e até mesmo teorizar. Para facilitar a proposição dos autores, apresenta-se a Figura 1:

Figura 1 Métodos Passivos e Ativos e Níveis de Aprendizado

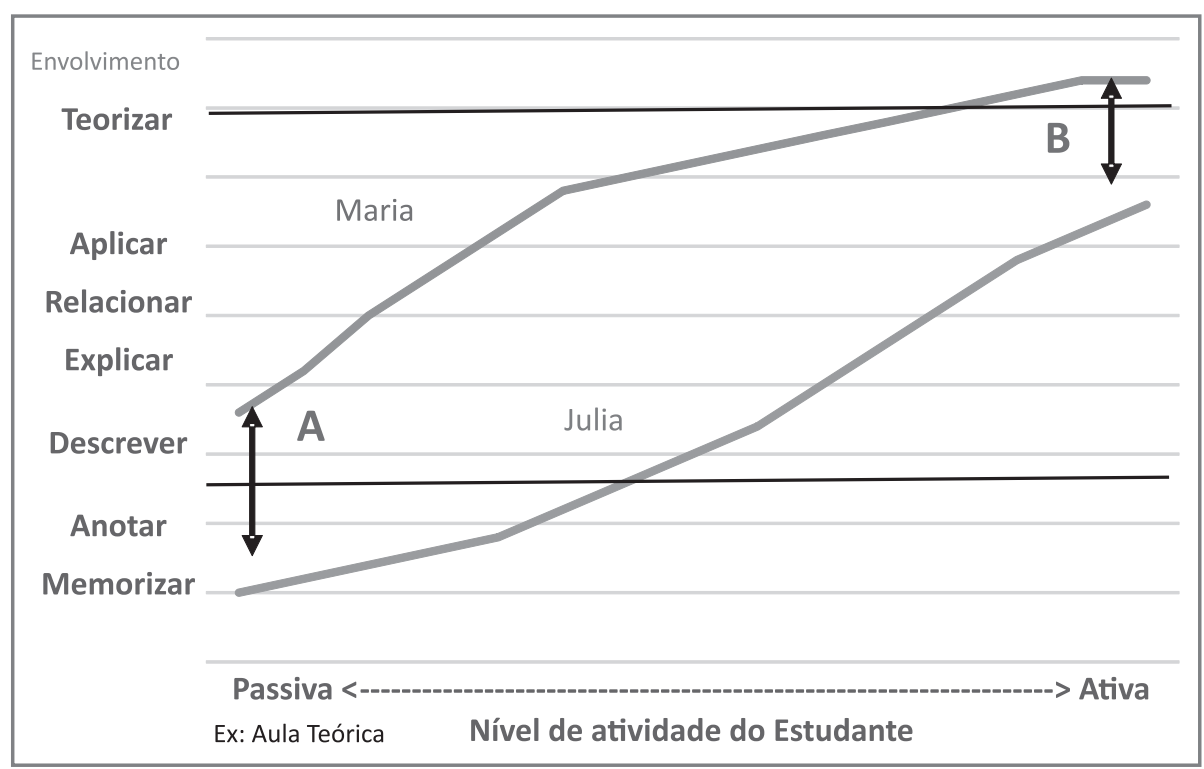

Fonte: Adaptado de Biggs e Tang (2007).

Por meio desse gráfico (Figura 1), pode-se compreender que a aprendizagem com base em problemas, ou seja, o Problem Based Learning (PBL), tende a favorecer o aprendizado. No caso do gráfico, buscou-se demonstrar que duas alunas - Maria e Julia - mesmo em níveis distintos de aprendizado individual (Maria tem mais capacidade de aprendizado que Julia - A), 
ao expô-las a métodos ativos, o nível de aprendizado de ambas aumenta e, mesmo nas condições menos favoráveis do aprendizado de Julia, o gap entre elas tende a diminuir (B).

Entretanto nem todos os prêmios e concursos nasceram com a ideia de contribuir com o conhecimento e a habilidade de estudantes. Nesse sentido, ao pesquisarem os prêmios de sustentabilidade, Bastos, Kuuluvainen e Braga (2015) constataram que alguns dos organizadores de prêmios consideravam, desde o seu planejamento, o processo de melhoria de aprendizagem em seus propósitos (BASTOS; KUULUVAINEN; BRAGA, 2015).

Conforme levantamento realizado pela McKinsey, em 2009, a partir da sua base de dados dos principais prêmios no mundo (universo de 30 mil prêmios), foi verificado, com patrocinadores e organizações, que 35\% deles tinham como objetivo a melhoria das habilidades e dos conhecimentos dos participantes. Ou seja, pouco mais de um terço dos prêmios e concursos teria as características necessárias para ser utilizado como alternativa de aprendizagem.

\section{PREAMIOS E CONCURSOS VERSUS METODOLOGIAS ATIVAS}

Os métodos passivos de aprendizagem são utilizados com frequência nas faculdades de Administração. Num país continental como o Brasil, a realidade das IES, de norte a sul, de leste a oeste, diferencia-se a ponto de reconhecer que uma faculdade de Administração que tenha uma biblioteca e uma sala com giz seja algo avançado para as regiões mais pobres e distantes do país (SPINK, 2004).

A despeito das diferenças entre as IES no país, os pesquisadores da área de ensino e aprendizagem tendem a concordar sobre a necessidade de um sistema de ensino mais centrado no aluno, baseado em experiências, vivências e no qual o docente é um facilitador e promotor do processo de ensino e aprendizagem (ALCADIPANI; BRESLER, 2000; NICOLINI, 2003; MASSETO, 2007; ALCADIPANI, 2011a; ALMEIDA et al., 2011).

No Quadro 1, destacam-se os métodos ativos e passivos mais comuns no ensino da Administração, conforme classificação dos métodos de ensino em ativos e passivos organizados por Oliveira, Muritiba e Casado (2005): 
Quadro 1 Métodos de Ensino Ativos (MA) e Passivos (MP)

\begin{tabular}{|cc|}
\hline Métodos Atrvos & MÉtodos PAssivos \\
\hline Casos para Ensino & Aula expositiva \\
Discussões e debates em grupo & Uso da lousa e data-show \\
Jogos de Empresas & Palestra \\
Simulações & Leitura de livros e textos \\
Serious Game & Pesquisa bibliográfica \\
Atuação em Empresa Júnior & \\
Teatro, música e dramatizações & \\
Produção de filmes & \\
\hline
\end{tabular}

Fonte: Adaptado de Oliveira, Muritiba e Casado (2005, p. 7).

O processo de aprendizado divide-se em quatro etapas que se repetem num ciclo (OLIVEIRA; MURITIBA; CASADO, 2005), destacam-se métodos de ensino ativos para desenvolver a capacidade do aluno em resolver problemas. A Figura 2 ilustra as quatro etapas do chamado ciclo de Kolb, com o qual busca-se mostrar o processo de aprendizagem:

Figura 2 Ciclo de Kolb

\begin{tabular}{|c|c|c|}
\hline $\begin{array}{c}\text { Experiência Concreta } \\
\text { Envolver-se em uma atividade } \\
\text { Trabalho de campo, observações, } \\
\text { jogos, filmes, etc. }\end{array}$ & $\rightarrow$ & $\begin{array}{l}\text { Observação Reflexiva } \\
\text { Olhar a atividade sob diferentes } \\
\text { perspectivas } \\
\text { Debates, discussões, reflexões. }\end{array}$ \\
\hline$\uparrow$ & & $\downarrow$ \\
\hline $\begin{array}{c}\text { Conceituação Abstrata } \\
\text { Criar conceitos e hipóteses } \\
\text { Criar analogias, construir mode- } \\
\text { los e escrever artigos científicos. }\end{array}$ & $\leftarrow$ & $\begin{array}{l}\text { Experimentação Ativa } \\
\text { Usar teorias e modelos para } \\
\text { resolver problemas } \\
\text { Artigos, estudos de caso, projetos, } \\
\text { simulações. }\end{array}$ \\
\hline
\end{tabular}

Fonte: Oliveira, Muritiba e Casado (2005, p. 4) 
O ciclo de Kolb inicia com uma experiência concreta; e, com base nela, os alunos são envolvidos nas atividades. Em seguida, parte-se para a observação reflexiva, ou seja, buscam-se elementos e pontos de vista distintos, de tal forma que se construa uma compreensão com base em diferentes prismas. Como próximo passo, os discentes procuram experimentar, de forma ativa, modelos e teorias, ou seja, verificam, na prática, em que medida o arcabouço teórico os auxilia em suas atividades de resolução de problemas. Finalmente, busca-se fechar o ciclo com um processo reflexivo e abstrato, pelo qual os alunos são incentivados a criarem conceitos e hipóteses. Ao fechar um ciclo, os estudantes tendem a amadurecer seus conhecimentos, e isso, provavelmente, ajudará numa compreensão mais profunda da realidade e das experiências concretas.

De fato, os métodos de ensino ativos buscam incentivar os alunos a serem protagonistas, isto é, são instigados a inovar e solucionar problemas. Os alunos buscam o conhecimento de maneira ativa, de acordo com os desafios práticos a que são expostos. Nesse sentido, o professor passa a orientar os alunos, que, por sua vez, passam a tomar a frente nas situações e, com base na prática, aprendem a inovar, resolver problemas e adaptar-se a mudanças (OLIVEIRA; MURITIBA; CASADO, 2005).

Ao ter como base a pesquisa da equipe sueca formada por Bastos, Kuuluvainen e Braga (2015), que investigaram iniciativas de reconhecimento na área de sustentabilidade, apresenta-se o Quadro 2, que sintetiza uma comparação entre as metodologias ativas e o PBL e os prêmios e concursos:

Quadro 2 Metodologias Ativas e PBL versus Prêmios e Concursos

\begin{tabular}{|ccc|}
\hline & $\begin{array}{c}\text { METODOLOGIAS } \\
\text { ATIVAS E PBL }\end{array}$ & $\begin{array}{c}\text { PRÊMios E } \\
\text { Concursos }\end{array}$ \\
\hline $\begin{array}{c}\text { Aspectos } \\
\text { relacionados à } \\
\text { colaboração }\end{array}$ & $\begin{array}{c}\text { Colaboração é importante } \\
\text { para a resolução de } \\
\text { problemas }\end{array}$ & $\begin{array}{c}\text { Em geral, estimula-se a } \\
\text { colaboração }\end{array}$ \\
$\begin{array}{c}\text { Características } \\
\text { relacionadas aos } \\
\text { problemas reais }\end{array}$ & $\begin{array}{c}\text { Frequentemente tratam } \\
\text { de problemas reais }\end{array}$ & Tratam de problemas reais \\
\hline
\end{tabular}




\begin{tabular}{|c|c|c|}
\hline & $\begin{array}{l}\text { Metodologias } \\
\text { Ativas e PBL }\end{array}$ & $\begin{array}{l}\text { PRÊMIOS E } \\
\text { Concursos }\end{array}$ \\
\hline $\begin{array}{l}\text { Elementos } \\
\text { relacionados } \\
\text { aos problemas } \\
\text { complexos }\end{array}$ & $\begin{array}{c}\text { Existe complexidade nos } \\
\text { problemas abordados }\end{array}$ & $\begin{array}{l}\text { Os problemas são } \\
\text { frequentemente complexos }\end{array}$ \\
\hline $\begin{array}{l}\text { Quem são os } \\
\text { sujeitos de } \\
\text { aprendizagem }\end{array}$ & $\begin{array}{l}\text { Aprendizagem centrada } \\
\text { no aluno }\end{array}$ & $\begin{array}{c}\text { Aprendizagem tanto para } \\
\text { alunos como também para } \\
\text { professores }\end{array}$ \\
\hline $\begin{array}{l}\text { Período em que } \\
\text { ocorrem }\end{array}$ & $\begin{array}{l}\text { Em geral, no período } \\
\text { letivo dos cursos }\end{array}$ & $\begin{array}{c}\text { Nem sempre coincidem } \\
\text { com o período letivo dos } \\
\text { cursos }\end{array}$ \\
\hline $\begin{array}{l}\text { Quem promove } \\
\text { as atividades }\end{array}$ & $\begin{array}{l}\text { Os professores são os } \\
\text { principais responsáveis }\end{array}$ & $\begin{array}{l}\text { Atores externos do setor } \\
\text { público, privado ou da } \\
\text { sociedade civil }\end{array}$ \\
\hline $\begin{array}{l}\text { Principais } \\
\text { estímulos }\end{array}$ & $\begin{array}{l}\text { Notas, participação e } \\
\text { feedbacks }\end{array}$ & $\begin{array}{l}\text { Reconhecimento, troféus, } \\
\text { medalhas, dinheiro, } \\
\text { viagens, equipamentos, etc. }\end{array}$ \\
\hline $\begin{array}{l}\text { Aspectos } \\
\text { relacionados à } \\
\text { diversidade }\end{array}$ & $\begin{array}{c}\text { Potencial para a } \\
\text { diversidade de } \\
\text { pessoas encontrem } \\
\text { soluções inovadoras e } \\
\text { diversificadas }\end{array}$ & $\begin{array}{c}\text { Potencial para a } \\
\text { diversidade de pessoas } \\
\text { encontrem soluções } \\
\text { inovadoras e diversificadas }\end{array}$ \\
\hline $\begin{array}{l}\text { Principais } \\
\text { críticas }\end{array}$ & $\begin{array}{l}\text { Nem todos os professores } \\
\text { aceitam mudar seu papel } \\
\text { no processo de ensino e } \\
\text { aprendizagem; nem } \\
\text { todos os estudantes } \\
\text { querem assumir mais } \\
\text { trabalho e atividades, } \\
\text { tampouco estão } \\
\text { acostumados a "tomar a } \\
\text { iniciativa". }\end{array}$ & $\begin{array}{l}\text { A excessiva competição } \\
\text { pode levar os alunos a } \\
\text { fraudarem sistemas. O } \\
\text { sentimento de perda } \\
\text { ou derrota, se mal } \\
\text { administrado, pode gerar } \\
\text { consequências ruins aos } \\
\text { alunos e até mesmo aos } \\
\text { docentes. }\end{array}$ \\
\hline
\end{tabular}

Fonte: Adaptado de Bastos, Kuuluvainen e Braga (2015, p. 24) 
Apesar de nem sempre estarem em sintonia com o calendário acadêmico e fora do controle e da gestão do docente, os prêmios e concursos universitários se aproximam das características das metodologias ativas de aprendizado. Ou seja, isso parece ser um indício de que docentes, discentes e até mesmo as instituições de ensino podem fazer uso desse tipo de iniciativa em benefício do processo de ensino e aprendizagem. 


\section{PERCURSO METODOLÓGICO}

A pesquisa enquadra-se como uma investigação do tipo exploratória, de cunho qualitativo e de natureza aplicada. Quanto aos procedimentos técnicos, utilizaram-se referências acadêmicas relacionadas à temática - artigos, livros, teses e dissertações. Aplicaram-se questionários semiestruturados com o Coordenador do curso de Administração e a Pró-Reitora de Extensão da IES. Os alunos vencedores e participantes de prêmios da IES foram abordados em entrevistas não estruturadas (LAKATOS; MARCONI, 1991; GIL, 2002; SEVERINO, 2014).

Foram quatro grandes etapas necessárias para a realização da pesquisa:

Etapa 1 - Escutas não estruturadas de professores e alunos

- entre 2014 e 2015

Houve uma etapa "anterior" da pesquisa propriamente dita, na qual o pesquisador ouviu docentes e discentes sobre práticas inovadoras e exitosas de ensino e aprendizagem. Essa foi uma etapa livre de investigação, ou seja, não se tinha um objetivo claro nem a priori de pesquisa. As conversas ocorreram na sala dos professores, no espaço reservado para bate-papo e café e em conversas informais com estudantes.

Do ponto de vista acadêmico, os prêmios se constituem numa temática inédita de pesquisa no campo do ensino e da aprendizagem em Administração, de acordo com o levantamento que se fez em base de dados (a ser explicado adiante). Contudo, tacitamente, os prêmios e concursos são parte do universo de docentes e discentes. O pesquisador foi estimulado a esse tipo de pesquisa por perceber que alunos e professores da IES encontravam-se estimulados a alcançarem bons resultados nos prêmios e concursos e isso, provavelmente, tinha relação com o processo de aprendizagem. Foi a partir disso que se percebeu a lacuna existente em pesquisas sobre prêmios e concursos universitários. Esse processo de escuta ocorreu entre os anos de 2014 e 2015. 
Etapa 2 - Levantamento e Sistematização das Referências

- entre novembro de 2015 e abril de 2016

Como próximo passo, passou ao processo de levantamento e sistematização das referências. Notou-se a ausência de pesquisas sobre este assunto no Brasil. Partiu-se para uma investigação em âmbito internacional. Utilizou-se como sistemas de busca a base de dados Spell; Banco de Teses da USP; EBSCO, ProQUEST e Google Acadêmico. Alcançou-se um total de 28 referências entre teses, dissertações, artigos acadêmicos e executivos. Parte desse levantamento foi apresentada na revisão teórica. Essa etapa da pesquisa ocorreu entre os meses de novembro de 2015 e abril de 2016.

Os materiais localizados faziam menção aos prêmios e concursos, mas não se encontrou publicações acadêmicas em língua portuguesa que fizessem a relação entre prêmios e concursos universitários e aprendizagem em Administração. Por essa razão, a base teórica foi extraída, sobretudo, da literatura estrangeira.

Etapa 3 - Montagem de Banco de Dados

- entre novembro de 2014 e setembro de 2015

Procedeu-se a um levantamento e à montagem de um banco de dados com os prêmios e concursos universitários no Brasil. Essa etapa ocorreu entre os meses de novembro de 2014 e setembro de 2015. Utilizou-se o sistema de busca do Google com as palavras "prêmios"; "prêmios universitários"; "concursos"; "concursos universitários". Cabe esclarecer que a seleção dos prêmios e concursos levou em consideração o caráter didático deles, pois há iniciativas que se assemelham a loterias, sorteios, promoção de empresas, etc. Conforme estudos anteriores (McKinsey, 2009) apenas 35\% do total de prêmios estão relacionados a algum tipo de aprendizagem.

Nesse contexto, chegou-se ao universo de 46 (quarenta e seis) prêmios e concursos universitários no Brasil. Houve uma revisita aos sites dos prêmios localizados e percebeu-se que nem todos estavam ativos, de acordo com o que se levantou entre novembro de 2014 e setembro de 2015. 
Optou-se por desconsiderar os que se encontravam inativos em meados de 2016. O que se notou, com o processo de montagem da base de dados sobre prêmios e concursos, é que se trata de um tipo de atividade que não é contínua e regular, ou seja, algumas iniciativas relevantes no passado recente não se encontram mais ativas. Cita-se o exemplo do Prêmio FENEAD, que durou cerca de 10 anos (entre 1996 e 2005) e estimulou estudantes e professores a realizarem projetos sociais. Essa iniciativa foi encerrada e, portanto, não se considerou esse tipo de prêmio ou concurso na base de informações apresentadas. Assim, chegou-se a um conjunto de 30 prêmios. Essa etapa era necessária, pois foi estabelecida como um dos objetivos a busca pelos prêmios e concursos universitários no Brasil.

Etapa 4 - Sistematização, Entrevistas e Redação do Artigo - entre agosto de 2015 e abril de 2016

Após a sistematização de parte das referências teóricas e dos prêmios e concursos existentes no país, agendaram-se entrevistas com o Coordenador do curso de Administração e a Pró-Reitora de Extensão da IES pesquisada. As conversas duraram em torno de 45 minutos. Elas foram gravadas e transcritas integralmente. De posse dos resultados, partiu-se para a redação do artigo. 


\section{RESULTADOS E ANÁLISE}

O levantamento de prêmios e concursos universitários no Brasil alcançou um total de 46 (quarenta e seis) iniciativas, dessas, 30 (trinta) mantêm-se ativas, assim, para melhor entendimento e compreensão, apresenta-se esse levantamento no Quadro 3:

Quadro 3 Prêmios e Concursos Universitários Ativos no Brasil

\begin{tabular}{|c|c|}
\hline 1. TRANSFORMA BRASIL & $\begin{array}{l}\text { 2. DESAFIO UNIVERSITÁRIO } \\
\text { EMPREENDEDOR }\end{array}$ \\
\hline $\begin{array}{l}\text { Promotor: Instituto de Cidadania } \\
\text { Empresarial (ICE), Centro de } \\
\text { Empreendedorismo em Novos Negócios } \\
\text { da Fundação Getúlio Vargas. }\end{array}$ & $\begin{array}{l}\text { Promotor: Serviço Brasileiro de } \\
\text { Apoio às Micro e Pequenas Empresas } \\
\text { (SEBRAE). }\end{array}$ \\
\hline Ano de lançamento: 2013 & Ano de lançamento: 2000 \\
\hline $\begin{array}{l}\text { Objetivo: Promover e fortalecer o } \\
\text { tema de negócios sociais entre os } \\
\text { alunos universitários de todo Brasil, } \\
\text { estimulando projetos que demonstrem } \\
\text { potencial de produzir impacto social e/ } \\
\text { ou ambiental relevantes. } \\
\text { Site: } \text { http://www.transformabrasil.com. } \\
\text { br/index.php }\end{array}$ & $\begin{array}{l}\text { Objetivo: Desenvolver atitudes } \\
\text { empreendedoras e preparar-se para os } \\
\text { desafios do mercado de trabalho. } \\
\text { Site: http:// } \\
\text { desafiouniversitarioempreendedor. } \\
\text { sebrae.com.br/plataforma/index.xhtml }\end{array}$ \\
\hline 3. PRÊMIO JOVEM CIENTISTA & $\begin{array}{l}\text { 4. PRÊMIO FECOMERCIO DE } \\
\text { SUSTENTABILIDADE }\end{array}$ \\
\hline $\begin{array}{l}\text { Promotor: Centro Nacional de } \\
\text { Desenvolvimento Científico e } \\
\text { Tecnológico (CNPq), Fundação } \\
\text { Roberto Marinho, Gerdau e GE. }\end{array}$ & $\begin{array}{l}\text { Promotor: Federação do Comércio de } \\
\text { Bens, Serviços e Turismo do Estado de } \\
\text { São Paulo (FecomercioSP) em parceria } \\
\text { com a Fundação Dom Cabral. }\end{array}$ \\
\hline Ano de lançamento: 1981 & Ano de lançamento: 2008 \\
\hline $\begin{array}{l}\text { Objetivo: Revelar talentos, impulsionar } \\
\text { a pesquisa no país e investir em } \\
\text { estudantes e jovens pesquisadores } \\
\text { que procuram inovar na solução dos } \\
\text { desafios da sociedade. } \\
\text { Site: http://www.jovemcientista.cnpq.br/ }\end{array}$ & $\begin{array}{l}\text { Objetivo: Ideias inovadoras para } \\
\text { reduzir impactos econômicos, sociais e } \\
\text { ambientais em escala local ou global. } \\
\text { Site:http://www.fecomercio.com. } \\
\text { br/?option=com_eventos\&view= } \\
\text { interna\&Itemid=21\&id=6669 }\end{array}$ \\
\hline
\end{tabular}




\begin{tabular}{|c|c|}
\hline $\begin{array}{l}\text { 5. PRÊMIO SANTANDER } \\
\text { EMPREENDEDORISMO }\end{array}$ & $\begin{array}{l}\text { 6. PRÊMIO SANTANDER CIÊNCIA E } \\
\text { INOVAÇÃO }\end{array}$ \\
\hline Promotor: Santander & Promotor: Santander \\
\hline Ano de lançamento: 2005 & Ano de lançamento: 2005 \\
\hline $\begin{array}{l}\text { Objetivo: Reconhecer projetos } \\
\text { estudantis com postura empreendedora } \\
\text { Site: https://www.santander. } \\
\text { com.br/portal/wps/gcm/package } \\
\text { /wps/universidades_14062013_80 } \\
\text { 313.zip/correntistas_conta_premios. } \\
\text { htm }\end{array}$ & $\begin{array}{l}\text { Objetivo: Estimular produção científica } \\
\text { de caráter inovador. } \\
\text { Site: https://www.santander. } \\
\text { com.br/portal/wps/gcm/package } \\
\text { /wps/universidades_14062013_80 } \\
\text { 313.zip/correntistas_conta_premios. } \\
\text { htm }\end{array}$ \\
\hline $\begin{array}{l}\text { 7. TORNEIO GERENCIAL } \\
\text { Promotor: Bernard Simulação }\end{array}$ & $\begin{array}{c}\text { 8. PRÊMIO ODEBRECHT } \\
\text { PARA O DESENVOLVIMENTO } \\
\text { SUSTENTÁVEL }\end{array}$ \\
\hline Ano de lançamento: 1998 & $\begin{array}{l}\text { Promotor: Organização Odebrecht } \\
\text { Ano de lancamento: } 2005\end{array}$ \\
\hline $\begin{array}{l}\text { Objetivo: Tem o objetivo de possibilitar } \\
\text { aos participantes o exercício da gestão } \\
\text { empresarial, por meio de simulações, } \\
\text { para fins de aprimoramento e } \\
\text { capacitação. } \\
\text { Site: } \text { http://torneiogerencial.com.br/ } \\
\text { index.php }\end{array}$ & $\begin{array}{l}\text { Objetivo: Reconhecer e incentivar } \\
\text { os jovens universitários que se } \\
\text { propõem a pensar a engenharia em } \\
\text { uma perspectiva sustentável e gerar } \\
\text { conhecimento sobre o tema, difundindo } \\
\text { essas novas ideias na comunidade } \\
\text { acadêmica brasileira e sociedade em } \\
\text { geral. } \\
\text { Site: http://www.premioodebrecht.com/ } \\
\text { brasil/\#!\# }\end{array}$ \\
\hline
\end{tabular}




\section{PRÊMIO EDP INOVAÇÃO}

Promotor: EDP - Energias do Brasil

S.A.

Ano de lançamento: 2010

Objetivo: Incentivar a inovação, a sustentabilidade e o empreendedorismo no Brasil por meio do estímulo ao desenvolvimento de novas tecnologias e novos modelos de negócios para cidades inteligentes.

Site: http://premioedp2020.ning.com/ opremio

\section{COMPETIÇÃO FÓRMULA SAE BRASIL}

Promotor: SAE BRASIL

Ano de lançamento: 2012

Objetivo: Propiciar a difusão e o intercâmbio de técnicas e conhecimentos de Engenharia Automotiva entre estudantes e futuros profissionais da engenharia da mobilidade, focalizando na nova geração de veículos elétricos (Tecnologia Híbrida deve ser de transição), por meio de aplicações práticas e da competição entre equipes. Site: http://www.saebrasil.org.br/ eventos/programas_estudantis/formula 2013/Default.aspx

\section{COMPETIÇÃO FÓRMULA SAE BRASIL COMBUSTÃO}

\author{
Promotor: SAE BRASIL
}

Ano de lançamento: No Brasil, em 2004.

Objetivo: Propiciar a difusão e o intercâmbio de técnicas e conhecimentos de Engenharia formula náutica entre estudantes e futuros profissionais da engenharia da mobilidade, por meio de aplicações práticas e da competição entre equipes.

Site: http://www.saebrasil.org.br/ eventos/programas_estudantis/formula 2013/Default.aspx

\section{COMPETIÇÃO SAE BRASIL AERODESIGN}

\section{Promotor: SAE BRASIL}

Ano de lançamento: No Brasil, em 1999.

Objetivo: Propiciar a difusão e o intercâmbio de técnicas e conhecimentos de Engenharia Aeronáutica entre estudantes e futuros profissionais da engenharia da mobilidade, por meio de aplicações práticas e da competição entre equipes.

Site: http://www.saebrasil.org.br/ eventos/programas_estudantis/aero 2014/Default.aspx 


\section{COMPETIÇÃO BAJA SAE BRASIL-PETROBRAS}

Promotor: SAE BRASIL

Ano de lançamento: No Brasil, em 1994.

Objetivo: $\mathrm{O}$ projeto Baja SAE é um desafio lançado aos estudantes de engenharia que oferece a chance de aplicar na prática os conhecimentos adquiridos em sala de aula, visando incrementar sua preparação para o mercado de trabalho. Ao participar do projeto Baja SAE, o aluno se envolve com um caso real de desenvolvimento de projeto, desde sua concepção, projeto detalhado e construção.

Site: http://www.saebrasil.org.br/ eventos/programas_estudantis/baja 2014/Default.aspx

\section{CONCURSO TRAVESSIA FEI}

\section{Promotor: Centro Universitário FEI}

Ano de lançamento: 2009

Objetivo: O Concurso Travessia tem como objetivo agregar conhecimento, desenvolver e estimular novas habilidades nos estudantes, estimular o raciocínio, trabalho em equipe, a cooperação, entre muitos outros princípios e práticas essenciais para sua formação como estudante, futuro profissional e indivíduo.

Site: http://fei.edu.br/concursotravessia /2013/index.html

\section{MARATONA DE PROGRAMAÇÃO}

Promotor: Sociedade Brasileira de Computação

Ano de lançamento: 1996

Objetivo: A competição promove nos alunos a criatividade, a capacidade de trabalho em equipe, a busca de novas soluções de software e a habilidade de resolver problemas sob pressão. De ano para ano, temos observado que as instituições e principalmente as grandes empresas da área têm valorizado os alunos que participam da Maratona.

Site: http://maratona.ime.usp.br/

\section{INSTITUTO 3M PARA ESTUDANTES UNIVERSITÁRIOS}

Promotor: Instituto 3M de Inovação Social

Ano de lançamento: 2007

Objetivo: Apoiar projetos de extensão universitária voltados para promoção do desenvolvimento social a partir da utilização e do desenvolvimento de tecnologias sociais focalizadas em educação, saúde ou meio ambiente.

Site: http://www.3m.com/intl/br/mkt /instituto_3m_premio/ 


\section{PRÊMIO SANTANDER UNIVERSIDADE SOLIDÁRIA}

Promotor: Santander

Ano de lançamento: 2005

Objetivo: Contribuir com a formação cidadã do futuro profissional e inclusão social e econômica das comunidades com projetos com ênfase na geração de renda.

Site: https://www.santander. com.br/portal/wps/gcm/package /wps/universidades_14062013_80 313.zip/correntistas_conta_premios. htm

\section{PRÊMIO TESOURO NACIONAL}

Promotor: Secretaria do Tesouro

Nacional (STN) e Escola de

Administração Fazendária

Ano de lançamento: 1996

Objetivo: O Prêmio tem a finalidade de estimular a pesquisa na área de Finanças Públicas, reconhecendo os trabalhos de qualidade técnica e de aplicabilidade na Administração Pública.

Participantes: Estudantes de qualquer curso de graduação e pós-graduação.

Site: https://www.tesouro.fazenda.gov.br /pt/component/content/article/793

\section{BATALHA DE CONCEITOS}

Promotor: Battle of Concepts e Terra fórum/Globant

Ano de lançamento: 2006 (Brasil 2009)

Objetivo: Estimular a criatividade, ganhar experiência resolvendo casos reais de grandes empresas, ter a oportunidade de praticar a teoria aprendida em sala de aula e enriquecer o currículo.

Site: http://www.battleofconcepts.com. br/

\section{Promotor: Secretaria de}

Acompanhamento Econômico (SEAE) e Escola de Administração Fazendária

Ano de lançamento: 2006

Objetivo: O Prêmio tem a finalidade de estimular a pesquisa acerca dos temas subjacentes à defesa da concorrência e à regulação da atividade econômica e de difundir esses temas na comunidade acadêmica brasileira e sociedade em geral, reconhecendo os trabalhos de qualidade técnica e de aplicabilidade na Administração Pública.

Site: http://www.esaf.fazenda.gov.br/ premios/premios-1/ix-premio-seae2014-pagina-principal 


\section{PRÊMIO SOF DE MONOGRAFIAS}

Promotor: Secretaria de Orçamento Federal do Ministério do Planejamento, Orçamento e Gestão e Escola de Administração Fazendária.

Ano de lançamento: 2007

Objetivo: O Prêmio tem a finalidade de estimular a pesquisa sobre orçamento público, seus problemas, desafios e perspectivas, reconhecendo trabalhos de qualidade e de aplicabilidade na Administração Pública.

Site: http://www.esaf.fazenda.gov.br/ premios/premios-1/vii-premio-sof-2014

\section{PRÊMIO SERVIÇO FLORESTAL BRASILEIRO EM ESTUDOS DE ECONOMIA E MERCADO FLORESTAL}

Promotor: Serviço Florestal Brasileiro e Escola de Administração Fazendária

\section{Ano de lançamento: 2013}

Objetivo: O prêmio tem por finalidade estimular estudos de Economia e Mercado Florestal, focalizando a produção sustentável no Brasil, os seus desafios e perspectivas socioeconômicas e ambientais, e criar um portfólio de estudos que contribuam para o avanço da capacidade do SFB.

Site: http://www.esaf.fazenda.gov.br/ premios/premios-1/i-premio-servicoflorestal-brasileiro-em-estudos-deeconomia-e-mercado-florestal

\section{PRÊMIO MINISTÉRIO DA FAZENDA DE ECONOMIA}

Promotor: Ministério da Fazenda, Escola de Administração Fazendária e Associação Nacional de Centros de PósGraduação em Economia (Anpec).

Ano de lançamento: 2012

Objetivo: Divulgar novas ideias, estimular a produção científica e proporcionar ambiente de discussão em diversos campos do conhecimento econômico.

Site: http://www.esaf.fazenda.gov.br/ premios/premios-1/premio-ministerioda-fazenda

\section{COMPETIÇÃO DE RESOLUÇÃO DE CASOS}

\section{Promotor: FEA Júnior}

\section{Ano de lançamento: 2003}

Objetivo: Colocar em prática os conceitos aprendidos em sala de aula, além de vivenciar uma experiência não abrangida pelo currículo acadêmico.

Site: http://www.feajr.com/\#!competiode-resoluo-de-casos/clnci 


\section{PRÊMIO CNI DE ECONOMIA}

Promotor: CNI - Confederação

Nacional da Indústria.

Ano de lançamento: 2008

Objetivo: Tem por finalidade estimular a pesquisa econômica aplicada de alta qualidade sobre temas relevantes para a indústria brasileira e será regido pelo presente regulamento.

Site: http://www.portaldaindustria.com. $\mathrm{br} / \mathrm{cni} / \mathrm{canal} / \mathrm{premio}$-cni-de-economiahome/

\section{DESAFIO UNIVERSITÁRIO CAMARGO CORRÊA}

Promotor: Construtora Camargo

Corrêa

Ano de lançamento: 2013

Objetivo: O objetivo geral do desafio é propiciar um ambiente de geração de ideias de inovação com universitários que promova benefícios ao negócio da Camargo Corrêa no que diz respeito a soluções, potencialmente, inovadoras para um ou mais subtemas do Ciclo do Concreto. A proposta pode ser uma nova ideia, uma pesquisa em andamento ou uma prática existente em outro setor, mercado ou país.

Site: 83index://camargo.brightidea.com/ universidades

\section{6. 'YOUNG PERSONS' WORLD LECTURE COMPETITION'}

Promotor: Instituto de Materiais, Minerais e Mineração (IOM3).

Ano de lançamento: 2005

Objetivo: Tem objetivo de estimular e aprimorar a capacidade de comunicação de estudantes e jovens profissionais de até 28 anos. A competição busca, principalmente, melhorar a capacidade dos candidatos em expor temas complexos, de um modo claro e atraente para o público não especializado.

Site: http://www.iom3.org/wlc

\section{PRÊMIO LITERÁRIO ESCRITOR UNIVERSITÁRIO 'ALCEU AMOROSO LIMA'}

Promotor: Centro de Integração Empresa-Escola (CIEE)

Ano de lançamento: 2001.

Objetivo: O objetivo da premiação é estimular o gosto dos jovens pela leitura com base na escrita. Segundo a assessoria de imprensa do CIEE, a falta de leitura é um dos maiores problemas dos aprendizes nos processos seletivos.

Site: http://www.ciee.org.br/ portal/institucional/premio/abl/ regulamento13.asp 


\section{DESAFIO INTEL}

Promotor: Intel

Ano de lançamento: Não informado

Objetivo: O Desafio Intel fornece educação empresarial e imersão no Vale do Silício para as melhores startups de computação de estudantes universitários e recém-formados de toda a América Latina.

Site: http://desafiointel.com
30. PRÊMIO SARAIVA - MÚSICA E LITERATURA

\section{Promotor: Saraiva}

Ano de lançamento: 2014

Objetivo: Fomentar a Arte Literária e a Arte Musical, mediante a premiação das melhores obras literárias e talentos musicais.

Site: http://www.premiosaraiva.com.br

Fonte: Pesquisa Exploratória de Prêmios e Concursos Universitários no Brasil (2016).

Os prêmios e concursos caracterizam-se por estimular diferentes competências, técnicas e conhecimentos. Após a leitura e análise dos 30 prêmios e concursos localizados, foi possível perceber seis categorias:

1) Parte deles incentiva a capacidade empreendedora dos estudantes, tais como o Santander de Empreendedorismo, o Transformar Brasil, Desafio Universitário Camargo Corrêa, Batalha de Conceitos e o Desafio Universitário Empreendedor.

2) Uma segunda categoria de prêmios localizada foi a que busca estimular a competência acadêmica e científica, tais como o Prêmio CNI de Economia, Prêmio SOF de monografia, Prêmio Ministério da Fazenda, Prêmio Tesouro Nacional, o Prêmio Santander de Ciência e Tecnologia e o Prêmio Jovem Cientista.

3) Outros prêmios e concursos visam a reconhecer capacidades no campo da arte e cultura, tais como o Prêmio Saraiva - Música e Literatura e o Prêmio Literário Escritor Universitário Alceu Amoroso Lima.

4) Por fim, foram localizadas iniciativas que incentivam a capacidade de resolução de casos e problemas que podem ser exemplificados pelo Desafio de Casos (FEA-USP) e a Maratona de Programação. 
5) Outros ainda buscam incentivar uma visão cidadã (Prêmio Odebrecht de Sustentabilidade e do Instituto 3M para Universitários).

6) Também o aprendizado de oratória e comunicação, sendo o exemplo "Young Persons" World Lecture Competition.

Dessa forma, verificou-se uma diversidade temática dos prêmios e concursos. Encontrou-se desde prêmios para iniciativas de empreendedorismo social até para monografias em finanças públicas. Dado que se buscou um levantamento exploratório, incluíram-se prêmios de música e literatura ao mesmo tempo que foram consideradas as iniciativas de reconhecimento na área de tecnologia, serviço florestal, economia e desenvolvimento sustentável. Em termos gerais, observou-se que os cronogramas desses prêmios seguem um calendário próximo ao das IES, ou seja, tendem a favorecer a participação dos estudantes e professores. Além disso, há iniciativas de inscrição contínua, tal como o "Batalha de Conceitos", em que empresas lançam desafios e problemas de maneira contínua e com prazos variáveis.

Foi possível verificar que os prêmios universitários existem no Brasil desde a década de 1980. Do seu início aos anos 2000, foram lançados sete prêmios; de 2001 em diante, 23 prêmios. Ou seja, houve um crescimento no número de prêmios e concursos universitários na década de 2000 e parece haver uma tendência nesse sentido, conforme apresentado no Gráfico 1. 
Gráfico 1 Anos de Criação dos Prêmios e Concursos Universitários no Brasil

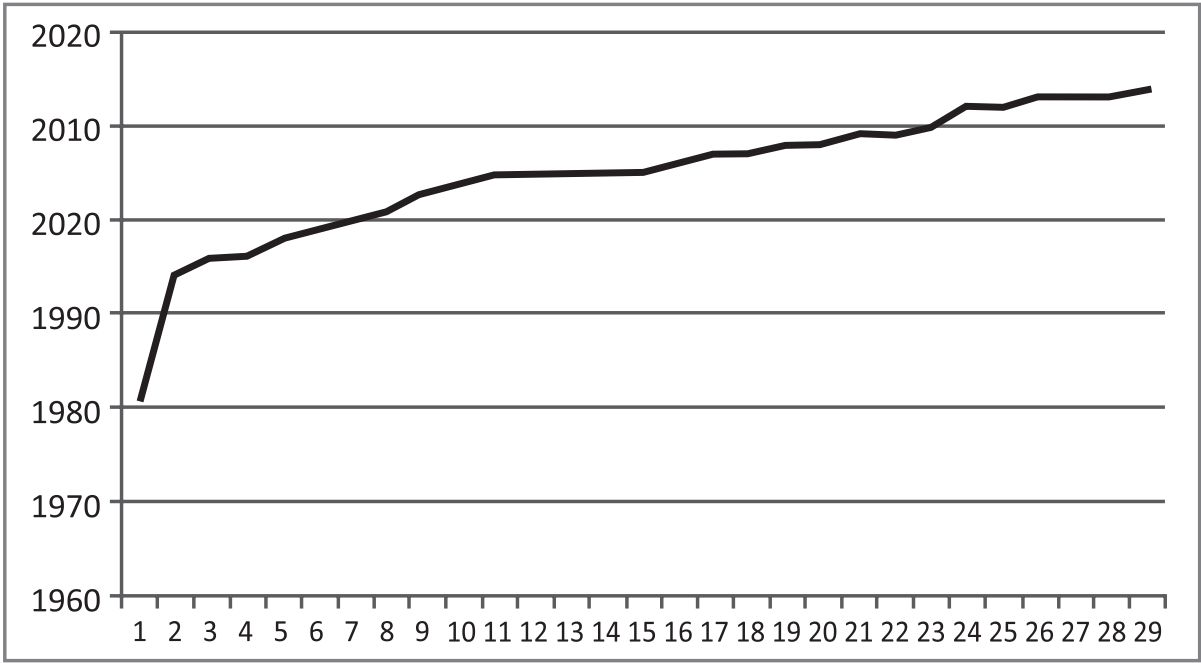

Como próxima etapa, partiu-se para a análise das conversas e entrevistas com alunos, professores e dirigentes da IES pesquisada.

\section{AS ENTREVISTAS EXPLORATÓRIAS}

Os alunos consultados tinham interesse em prêmios e concursos universitários, mas desconheciam a maioria daqueles que foram apresentados na lista. Alguns desses alunos tinham participado ou mesmo conquistado algum reconhecimento. Os que lograram alguma forma de reconhecimento tinham um posicionamento entusiasmado e positivo com esse tipo de iniciativa; essa posição, porém, não foi verificada com colegas que apenas participaram. Um deles, inclusive, demonstrou arrependimento e decepção com os organizadores do prêmio do qual participara, não concordando com o resultado final.

Os professores, por sua vez, não se demonstraram interessados, num primeiro momento, sobre os prêmios e concursos. As conversas informais, ao longo de 2014 e 2015, indicaram uma parcela específica de professores que havia aderido a algum tipo de premiação (para si e/ ou para seus alu- 
nos) - algo em torno de $10 \%$ do total de docentes. Da lista de prêmios, a maioria deles não foi citada, inclusive pelos mais interessados no assunto. Contudo, ao serem abordados pela possibilidade de inserirem esse tipo de atividade - participação dos discentes em prêmios e concursos como uma alternativa de aprendizagem -, houve uma manifestação positiva dos docentes. Cerca de $30 \%$ dos que ainda não tinham participado desse tipo de iniciativa se colocaram numa posição interessada por essa forma de aprendizagem ativa.

As entrevistas com os dirigentes da IES - Coordenador de Curso de Administração e a Pró-Reitora - duraram, em média, 45 minutos. Questionados sobre o que são os prêmios universitários, a Pró-Reitora disse o seguinte: 'Não conheço uma definição exata de prêmios universitários, mas tenho acompanhado alguns concursos e desafios universitários como Desafio Sebrae, Santander Universidades e desafios voltados à engenharia.

O Coordenador de Curso, por sua vez, comentou: "tenho conhecimento de concursos e prêmios atuais como o concurso de Águas da FIESP e o Desafio EDP da Telecom Portugal". Ambos os gestores têm acompanhado alguns dos prêmios e concursos universitários, mas não souberam expressar uma definição conceitual sobre o assunto.

Ao ser questionada sobre o que considerava importante para estimular a participação discente nos prêmios e concursos, a Pró-Reitora argumentou assim: "Considero importante que exista a motivação dos discentes, assim como os professores precisam estar interessados e envolvidos, além do apoio institucional". De forma distinta, e talvez complementar, o Coordenador de Curso chamou atenção para um ponto, qual seja, "os prêmios e concursos precisam estar alinhados ao tripé estratégico da instituição, ou seja, que objetivem a melhoria econômica, social e ambiental, assim como as demandas da sociedade". De fato, os dirigentes buscaram destacar elementos complementares - o interesse dos alunos e professores e que os prêmios e concursos tinham de se alinhar com a estratégia da IES.

Indagados a respeito do que os prêmios e concursos poderiam agregar à IES, ambos os gestores reconhecem a importância desse tipo de ini- 
ciativa: "alavancam o reconhecimento da instituição" e "traz mais reconhecimento da IES pelo mercado", falas da Pró-Reitora e Coordenador de Curso, respectivamente. A Pró-Reitora reconheceu, ainda, a relevância dos prêmios e concursos para o aprendizado dos estudantes: "acredito que os prêmios são uma forma para motivar os alunos a buscarem conhecimento de maneira autônoma”. Ou seja, esta dirigente tende a reconhecer os prêmios e concursos como um espaço alternativo de aprendizagem no qual os estudantes são protagonistas.

Finalmente, os entrevistados apresentaram suas visões acerca da possibilidade de aumentar as chances da IES para ganhar mais prêmios e concursos universitários. Para a Pró-Reitora, a instituição já faz isso, mas considera que é possível aumentar a participação discente:

A IES já oferece estrutura para participação em prêmios, pois ela é detentora de diversos reconhecimentos ao longo de sua história. Contudo, pode-se melhorar, sobretudo, na quantidade de alunos participantes e isso pode gerar mais reconhecimentos num futuro breve.

O Coordenador de Curso, por sua vez, argumentou na direção do que a IES poderia realizar a favor dos alunos:

Acredito que o aumento na participação de alunos depende de algumas iniciativas como: informando aos alunos sobre os concursos ativos, indicando quais leituras são importantes e também promovendo capacitação no tema proposto pelo concurso.

Os dirigentes da IES demonstraram interesse pelos prêmios e concursos universitários. Apesar disso, desconheciam a maioria dos prêmios vigentes. Esse fato parece indicar uma possibilidade para que essa IES possa divulgar institucionalmente outros prêmios e concursos, de tal forma que mais alunos e professores possam envolver-se nesse tipo de atividade. Os dirigentes apresentaram argumentos consistentes quanto ao papel da IES no que se refere à participação de alunos e professores, destacando, inclusive, a importância de que isso esteja em sintonia com a missão institucional. 
Apenas a Pró-Reitora da IES reconheceu a importância dos prêmios e concursos em termos de aprendizado autônomo dos alunos. Entretanto isso pode ser apresentado ao Coordenador, pois ele seria o principal responsável pelo envolvimento dos docentes. Por fim, ambos reconheceram que ações simples, tais como informar os alunos dos prêmios em andamento, surtiriam bons resultados para a IES. 


\section{CONSIDERAÇÕES FINAIS}

Esta pesquisa exploratória guiada pelas perguntas: em que medida os prêmios e concursos universitários podem se constituir em espaços alternativos de aprendizagem? Quais são as referências teóricas e empíricas sobre o assunto? E, finalmente, a experiência isolada do docente pode ser relevante à IES e aos demais docentes desta IES? Pode-se dizer que a investigação alcançou êxito em suas pretensões.

Nesse sentido, os prêmios e concursos universitários parecem ser uma alternativa de aprendizagem aos universitários de Administração. E tal conclusão é possível em função dos seguintes fatores: a prática do docente que inspirou esta pesquisa foi confirmada pela literatura consultada, pelas entrevistas exploratórias com discentes, docentes e dirigentes da IES pesquisada. Parte das referências teóricas e empíricas foi apresentada nesta pesquisa. Buscou-se não apresentar os prêmios inativos ou que foram interrompidos, igualmente, não se inseriram referências que não fizeram sentido ao presente estudo. Finalmente, argumenta-se a favor da expansão da experiência isolada do docente para os demais professores da IES, pois, pelo que se pôde apreender nesta pesquisa, os prêmios e concursos podem servir como atividade complementar à formação dos alunos.

É preciso observar que os prêmios e concursos não são uma espécie de panaceia na melhoria do processo de ensino e aprendizagem. Por sua vez, foi verificado por esta pesquisa que essas iniciativas externas à IES podem agir de maneira sinérgica ao processo de ensino e aprendizagem que ocorre em sala de aula. E, conforme observado, não apenas os alunos aprendem com os prêmios e concursos, mas também os próprios docentes. Esse parece ser um diferencial em relação às demais metodologias ativas.

Além disso, deve-se reconhecer que os prêmios e concursos universitários não estão sob o controle da IES, tampouco dos docentes e discentes. E, conforme apontado na pesquisa da Mc Kinsey (2009), apenas 35\% desse tipo de iniciativa possuem o compromisso com o aprendizado e a melhoria das habilidades. Ou seja, é preciso parcimônia e critérios claros para introduzir (ou não) esse tipo de atividade na formação dos estudantes. Ademais, 
o nível de adesão verificado entre os docentes da IES (10\%) é baixo; e, mesmo contando com o interesse de outros docentes ( $30 \%$ dos que se interessaram durante a pesquisa), o índice ficaria menor do que a metade no âmbito da participação dos professores.

Apesar de se tratar de uma pesquisa exploratória, alguns aspectos merecem ser mencionados como pontos a serem melhorados. Em primeiro lugar, a pesquisa deve ser expandida para outras IES, de tal forma a possibilitar comparações e, talvez, conclusões mais assertivas. A pesquisa com os alunos e professores poderia ter sido realizada com mais profundidade, mas, por falta de tempo e recursos, manteve-se na etapa exploratória. Muito embora existam limitações de referências sobre este assunto, mesmo em âmbito internacional, há espaço para se acrescentar novas obras em pesquisas futuras. Além disso, em função dos resultados alcançados nesta pesquisa, acredita-se que a experiência do docente da IES possa servir de inspiração a professores de outras IES.

Diversos trabalhos podem ser desenvolvidos envolvendo os prêmios e concursos como temática central. Uma possibilidade de pesquisa é conhecer, em profundidade, docentes e discentes que participaram e venceram seus desafios, buscando-se analisar os fatores explicativos para o alcance desses êxitos. Vislumbram-se pesquisas com IES que têm vencido concursos e conquistado prêmios nacionais e internacionais no Brasil. Outra pesquisa possível é com os organizadores e patrocinadores de prêmios e concursos universitários, investigando em que medida suas expectativas têm sido alcançadas. Enfim, acredita-se que a presente pesquisa inaugura um leque de oportunidades para que a temática de prêmios e concursos universitários possa entrar na agenda de pesquisa dos que têm dedicado seu tempo à melhoria no processo de ensino e aprendizagem em Administração. 


\section{REFERÊNCIAS}

ALCADIPANI, R.; BRESLER, R. A macdonaldização do ensino. Carta Capital, 10 de Maio. São Paulo: Ed. 133, 1999.

ALCADIPANI, R. Academia e a fábrica de sardinhas. O\&S. Salvador, v. 18, n. 57, p 345348, 2011a.

Resistir ao produtivismo: uma ode à perturbação acadêmica. Cad. EBAPE.BR, Rio de Janeiro, v. 9, n. 4, opinião 3, p.1174-1178, dez. 2011b.

BALLANTYNE, P. Challenge Prizes: A Practice Guide. England: NESTA - Center for Challenge Prizes, 2014.

BASTOS, Y. B.; KUULUVAINEN, S.; BRAGA, C. S. Leveraging the learning experiences in sustainability-oriented Challenge Prizes. Sweden: Blekinge Institute of Technology Karlskrona, 2015.

BEST, J. Prize proliferation. Sociological Forum, v.23, n.1, p.1-27, 2008.

BIGGS, J.; TANG, C. Teaching for quality learning at university. Buckingham: Society for research into higher education, 2007.

FREIRE, P. Pedagogia do Oprimido. 13.ed. Rio de Janeiro: Paz e Terra, 1983.

FREY, B. S. Giving and receiving awards. Perspectives on Psychological Science, v. 1, n. 4, p. 377-388, 2006.

FREY, B. S.; NECKERMANN, S. Awards: a view from psychological economics.

Zeitschrift für Psychologie/Journal of Psychology, v. 216, n. 4, p. 198-208, 2008.

FREY, B. S.; GALLUS, J. Awards are a special kind of signal. Zurich: Center for Research in Economics, Management and the Arts (CREMA), 2014.

GIL, A. C. Como elaborar projetos de pesquisa. 4.ed. São Paulo: Atlas, 2002.

HARRISON, B.; JEPSEN, D. M. The career impact of winning an external work-related award. Journal of Vocational Behavior, v. 89, p. 21-31, 2015.

KAY, L. How do Prizes Induce Innovation? Learning from The Google Lunar X-Prize. EUA: Georgia Institute of Technology. Thesis for the Degree Doctor of Philosophy in the School of Public Policy, 2011.

LAKATOS, E. M.; DE ANDRADE MARCONI, M. Metodologia científica. São Paulo: Atlas, 1991.

MASSETO, M. T. Novas tecnologias e mediação pedagógica. São Paulo: Papirus, 2007.

MCKINSEY AND COMPANY. And the winner is... Capturing the promise of philanthropic prizes, 2009. 
NICOLINI, A. Qual será o futuro das fábricas de administradores?. RAE, Salvador, v. 43, n. 2, p. 44-54, abr./jun. 2003.

OLIVEIRA, P. M.; MURITIBA, S. N; CASADO, T. Diferenças individuais dos estudantes e preferência por métodos de ensino em Administração: uma aplicação dos tipos psicológicos de Jung, 2005. Brasília - DF: Anais do ENANPAD, 2005.

SEVERINO, A. J. Metodologia do trabalho científico. São Paulo: Cortez, 2014.

SPINK, P. A inovação na perspectiva dos inovadores. In: IX Congresso Internacional Del Clad Sobre La Reforma Del Estado Y De La Administración Pública, 2004, Madrid. 


\section{DADOS DOS AUTORES}

EDSON SADAO IIZUKA`esadao@fei.edu.br

Doutor em Administração Pública pela FGV-EAESP

Instituição de vinculação: Centro Universitário FEI

São Paulo/SP - Brasil

Áreas de interesse em pesquisa: Negócios Sociais, Ensino e Pesquisa em Administração e Gestão Social.

* Centro Universitário FEI-PPGA. Rua Tamandaré, $688 \quad 5^{\circ}$ andar Liberdade São Paulo/ SP $\quad 01525-000$. 